\title{
A Corpus-Driven Investigation of Chinese English Learners' Performance of Verb-Noun Collocation: A Case Study of Ability
}

\author{
Lixin $\mathrm{Xia}^{1}$ \\ ${ }^{1}$ Guangdong University of Foreign Studies, China \\ Correspondence: Lixin Xia, Guangdong University of Foreign Studies, Guangzhou, Guangdong, 510420, China. \\ E-mail: cdhuiyi@aliyun.com
}

Received: April 10, 2013 Accepted: May 2, 2013 Online Published: July 4, 2013

doi:10.5539/elt.v6n8p119 URL: http://dx.doi.org/10.5539/elt.v6n8p119

\begin{abstract}
The paper makes a contrastive study on the performance of verb-noun collocation given by Chinese EFL learners based on the CLEC, ICLE and BNC. First, all the concordance lines with the token "ability" in the CLEC were collected and analyzed. Then, they were tagged manually in order to sort out the sentences in the verb-noun collocation structure. After that, a contrast was made between the data in the three corpora. The study found that there was a distinct gap between the use of verb-noun collocation between English native speakers and Chinese EFL learners, and that Chinese EFL learners also gave less satisfactory performance in verb-noun collocation in terms of correctness and appropriateness.
\end{abstract}

Keywords: Learner Corpora, English Pedagogical Lexicography, English Language Teaching

\section{Introduction}

As is widely recognized, the importance of collocation for the learner can hardly be overemphasized, and their performance in using it affects the "naturalness" of their language production directly. Therefore, this study aims to assess Chinese learners' performance of $\mathrm{V}+\mathrm{N}$ collocation in their English texts based on the Chinese Learner English Corpus (CLEC).

The CLEC is made up of written texts by Chinese learners at different levels. As this study focuses on the collocation errors made by college students, we will select the texts written by college students, which amount to about 800,000 tokens in all.

Collocation errors in the CLEC were tagged as CC1 $(\mathrm{N}+\mathrm{N}), \mathrm{CC} 2(\mathrm{~N}+\mathrm{V}), \mathrm{CC} 3(\mathrm{~V}+\mathrm{N}), \mathrm{CC} 4(\mathrm{Adj}+\mathrm{N}), \mathrm{CC} 5$ $(\mathrm{V}+\mathrm{Adv})$ and CC6 (Adv+Adj). After retrieval, a total of 2,421 collocation errors have been collected, among which the type of CC3 errors reaches 1,352. Next comes CC4 (389), CC2 (300), CC1 (268), CC5 (95) and CC6 (25). The distribution of the six types of collocation errors is shown in Fig. 1.

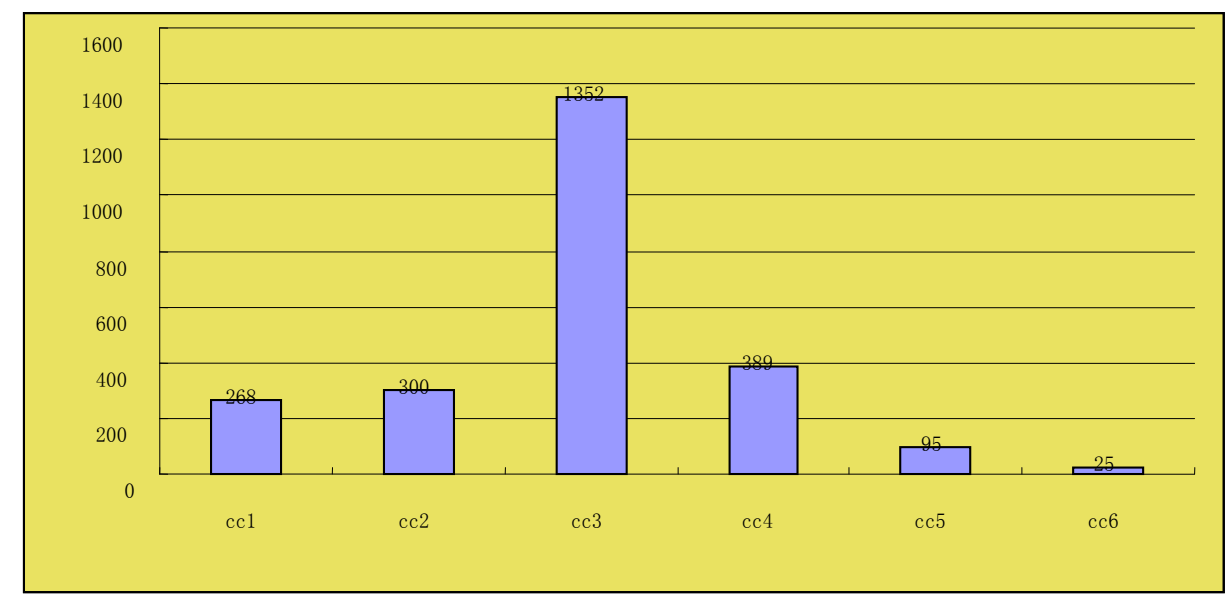

Figure 1. Distribution of the six types of collocation errors 
From Fig. 1, we can see that the number of $\mathrm{CC} 3$ is even greater than the sum of the other five types of errors. That is to say, Chinese learners are more likely to make collocation errors of $\mathrm{V}+\mathrm{N}$. That is the main reason why we focus our study on $\mathrm{V}+\mathrm{N}$ collocation.

\section{V+N Collocation Used by Chinese Learners and English Native Speakers}

To have a general picture of Chinese learners' use of the $\mathrm{V}+\mathrm{N}$ collocation, all the collocation errors tagged as CC3 in the CLEC were retrieved, and the ten lemmas with the greatest frequency were as follows: learn, knowledge, do, society, have, ability, make, job, get and success.

As ability has a high frequency in the CLEC and has not been chosen as a research object in previous studies, we will make a case study of ability. All the concordance lines with ability in the CLEC and BNC were retrieved, and its frequency in the two corpora was 313 and 10,389 respectively. Since the tokens in the subcorpora of college students in the CLEC and those in the BNC were at a ratio of 800,000 versus 100 million, the rate at which Chinese learners use the word ability was four times greater than that at which native English speakers did. So we can reach a conclusion that Chinese learners overused the word ability in their written texts.

By using the "Sketch Engine", we got all the V+N collocation of the word ability in the BNC, which amounted to 1,795 . Table 1 lists the first 51 verbs which collocate with the word ability in order of frequency.

Table 1. The collocates of "ability" in the BNC

\begin{tabular}{llllllll}
\hline Collocates & Freq. & Collocates & Freq. & Collocates & Freq. & Collocates & Freq. \\
\hline show & $\underline{79}$ & get & $\underline{28}$ & measure & $\underline{14}$ & destroy & $\underline{8}$ \\
\hline develop & $\underline{77}$ & lack & $\underline{27}$ & display & $\underline{13}$ & learn & $\underline{8}$ \\
\hline demonstrate & $\underline{66}$ & enhance & $\underline{25}$ & give & $\underline{13}$ & determine & $\underline{8}$ \\
\hline lose & $\underline{63}$ & reflect & $\underline{24}$ & involve & $\underline{12}$ & offer & $\underline{8}$ \\
\hline reduce & $\underline{51}$ & increase & $\underline{23}$ & read & $\underline{11}$ & see & $\underline{8}$ \\
\hline affect & $\underline{44}$ & use & $\underline{22}$ & find & $\underline{11}$ & inhibit & $\underline{7}$ \\
\hline doubt & $\underline{40}$ & assess & $\underline{20}$ & underestimate & $\underline{10}$ & admire & $\underline{7}$ \\
\hline require & $\underline{40}$ & need & $\underline{19}$ & recognize & $\underline{10}$ & evolve & $\underline{7}$ \\
\hline improve & $\underline{38}$ & restrict & $\underline{18}$ & examine & $\underline{10}$ & undermine & $\underline{7}$ \\
\hline limit & $\underline{35}$ & retain & $\underline{18}$ & question & $\underline{9}$ & strengthen & $\underline{7}$ \\
\hline include & $\underline{34}$ & acquire & $\underline{18}$ & confirm & $\underline{9}$ & organize & $\underline{7}$ \\
\hline test & $\underline{31}$ & impair & $\underline{17}$ & reveal & $\underline{9}$ & match & $\underline{7}$ \\
\hline possess & $\underline{29}$ & prove & $\underline{17}$ & describe & $\underline{9}$ & exercise & $\underline{7}$ \\
\hline
\end{tabular}

From Table 1, we can see that ability is usually used together with the verb show, develop, demonstrate, lose, reduce, etc. They can be classified into the following groups according to their literal meanings: develop/evolve ability, possess/retain ability, show/ demonstrate/ display/reveal/reflect ability, improve/ enhance/ strengthen/ increase ability, learn/acquire/get/find/see ability, admire/recognize ability, organize ability, use/exercise ability, prove/confirm ability, include/involve ability, read/describe/match ability, require/need ability, give/offer ability, test/ assess/ measure/examine ability, affect ability, doubt/question ability, underestimate/ determine ability, lose/lack/reduce/undermine ability, limit/restrict/inhibit ability, impair/destroy ability.

Then, all the concordance lines with the word ability were retrieved from the CLEC. After tagged manually, we got 212 instances of the $\mathrm{V}+\mathrm{N}$ collocation, among which 48 verbs were used together with the word ability as shown in Table 2. 
Table 2. The collocates of "ability" in the CLEC

\begin{tabular}{llllllll}
\hline Collocates & Freq. & Collocates & Freq. & Collocates & Freq. & Collocates & Freq. \\
\hline have & 61 & use & 3 & connect & 1 & justify & 1 \\
\hline improve & 36 & acquire & 2 & demonstrate & 1 & learn & 1 \\
\hline develop & 14 & forge & 2 & deny & 1 & maintain & 1 \\
\hline show & 14 & stand for & 2 & doubt & 1 & neglect & 1 \\
\hline find & 8 & strengthen & 2 & enforce & 1 & perform & 1 \\
\hline train & 8 & test & 2 & enhance & 1 & promote & 1 \\
\hline need & 6 & accumulate & 1 & enrich & 1 & raise & 1 \\
\hline prove & 6 & adapt & 1 & examine & 1 & resort to & 1 \\
\hline lose & 5 & appreciate & 1 & exert & 1 & reveal & 1 \\
\hline cultivate & 4 & block & 1 & form & 1 & stimulate & 1 \\
\hline display & 4 & bring about & 1 & gain & 1 & surpass & 1 \\
\hline practice & 3 & build & 1 & indicate & 1 & value & 1 \\
\hline
\end{tabular}

We grouped them in the same way and got the following groups: have/maintain ability, develop/cultivate/train ability, show/demonstrate/display/reveal/indicate/stand for ability, improve/enhance/strengthen/raise/promote ability, appreciate/value ability, learn/acquire/gain/find/accumulate/enrich/stimulate ability, use/exert/ perform/ practice/ enforce/resort to ability, forge/build/form/bring about ability, adapt ability, prove/justify ability, need ability, test/examine ability, doubt ability, lose ability, block ability, deny/neglect ability, surpass ability, connect ability.

Based on the above data, we might be able to draw the following conclusions:

First of all, Chinese learners tend to overuse some collocation structure. For example, while the frequency of the first ten collocations of ability in the BNC is only from 0.35 to 0.79 in one million, it is up to 5 to 18 in one million in Chinese learners' written texts. That is to say, it is from ten to a hundred times more chances for Chinese learners to use these ten collocations in their writings than for English native speakers do. Besides, the collocation "possess ... ability" occurs 29 times in the BNC, but none in the CLEC. The reason for this might be that Chinese learners have a limited size of vocabulary. Therefore, they have a tendency to choose the words and expressions that they feel safe to use. The collocation "have... ability" is an example of this, which was overused by Chinese learners in the CLEC. Similarly, the collocation "cultivate ... ability" appears four times in the texts in the CLEC, but only once in the BNC.

Next, compared with the phenomenon of overusing some collocations, the cases of underusing some collocations can be frequently found in Chinese learners' written texts. Sometimes the state of underuse is even more remarkable than that of overuse. The case of "possess ... ability" discussed above is an example of this. Moreover, Chinese learners are found to be particularly prone to underuse those collocation structures with negative semantic prosody. For example, English native speakers use such collocations as "lose/lack/reduce/undermine ability", "limit/ restrict/ inhibit ability" and "impair/destroy ability", etc. with a frequency of $63,27,51,7,35,18,7,17$ and 8 respectively for the collocates of lose, lack, reduce, undermine, limit, restrict, inhibit, impair and destroy in the BNC. But in the CLEC, only one collation with negative meaning was found, i.e. "lose ability". This shows that Chinese learners favor the use of collocations with positive semantic prosody, which might be caused by their negligence in acquiring collocations with negative semantic prosody.

Thirdly, the main causes for collocation errors are mother tongue transfer and intralingual transfer. Among the 48 $\mathrm{V}+\mathrm{N}$ collocations of ability in the CLEC, 16 of them didn't appear in the BNC. They were "train/forge/ build/ form/ accumulate/ enrich/raise/ enforce/ perform/deny/neglect/justify/ practice/ adapt/ surpass/ connect ability". Below are the instances of the 16 collocations excerpted from the CLEC:

1) $\mathrm{m} 1,-]$ for me. I think it not only train my ability [cc3,-] to adapt [vp1,-s] to

2) rk. [sn2,s] And so, they can forge their ability constantly, to adopt $[\mathrm{wd} 3,-3]$ 
3) ur problems into action, and build the ability to cope with many practice pro

4) $\mathrm{p} 1,-\mathrm{s}]$ that a lot of practice can form a ability of doing something. For exampl

5) e should accumulate knowledge and ability [cc3,4-] in usual time [np6

6) a good job they have to enrich their ability and have some special skill. I can

7) tant, as to [pp1,1-4] our people raise ability of identify.[sn2,s] So [wd5,-] the

8) should be preparing to enforce their ability in order to find a good job in the

9) le and how to perform $[\operatorname{cc} 3,-2]$ your ability well may be hard to realize

10) More [wd3,s-] I do not deny their ability to become rich. But I would not

11) for high scores and neglect other ability [np6,-] and actions [wd7,-] . In our

12) the teachers to justify $[\operatorname{cc} 3,-4]$ our ability and personality. Then we cou

13) I think I should practice all kinds of ability [np3,-]. Then when I enter

14) e same time, adapt to the progress of ability.[sn8,s] They can get $s$

15) ce pollutants discharged surpass the ability of natural purification, these places

16) t seems that we only connect our ability or cleverness with our theory examina

In the above examples, Ex. 1, Ex. 2 and Ex. 7-9 were the direct result of using a Chinese collocation. Thus, we had the collocations of "train/ forge/ build/form/ raise/ enforce/ perform...ability". Ex. 5, Ex. 6 and Ex. 12 were the result of intralingual transfer. In Ex. 5, the predicate verb accumulate was followed by two objects, the first of which was correct, but the last of which is not natural. In Ex. 6, imagination and experience were possible collocates of the verb enrich, but ability was not. In Ex. 12, the learner might intend to express the meaning of "prove our ability", but he used justify instead. For the rest of the examples, they should not be regarded as wrong collocations as they didn't violate the collocation rule.

Last but not the least, some forms of the $\mathrm{V}+\mathrm{N}$ collocation listed above were not tagged as a collocation error of CC3 in the CLEC. Only Ex. 1, Ex. 5, Ex. 9 and Ex. 12 were tagged as CC3. However, some collocations used by English native speakers were listed as collocation errors in the CLEC as follows:

17) ause they have many chances to show their ability [cc3,2-]. They also think ou

18) iving better, the person can display his ability, [cc3,2-] wise [wd2,s-] and suc

19) the one you like best and can value your ability. [cc3, 2-] Everything is decid

20) $\mathrm{d}$ he been so lonely. He was fired and took $[\operatorname{cc} 3,-3]$ great effort to find a new $\mathrm{j}$

21) s to crime easily. Usually, we give $[\operatorname{cc} 3,-2]$ great sympathy to those criminals

This might be caused by the negligence of the corpus builders. Although this may decrease the accuracy of the corpus data, it won't have much influence on the analysis of the characteristics of collocation errors made by Chinese learners.

\section{A Contrastive Study on the Collocation Used by Chinese Learners and International Learners}

As the ICLE is an untagged corpus, we selected the written texts by English learners in Spain, France, Netherlands, Finland and Czechoslovakia randomly, which added up to about 800,000 tokens. Therefore, the amount of data chosen from the two learner corpora and the register of the written texts were comparable, which guarantees the validity of the comparison.

Table 3. The collocates of "ability" in the ICLE

\begin{tabular}{llllllll}
\hline Collocates & Freq. & Collocates & Freq. & Collocates & Freq. & Collocates & Freq. \\
\hline have & 14 & demonstrate & 1 & demand & 1 & omit & 1 \\
\hline Lose & 10 & impair & 1 & descapacite & 1 & show & 1 \\
\hline Use & 3 & reduce & 1 & possess & 1 & support & 1 \\
\hline Prove & 2 & create & 1 & retain & 1 & develop & 1 \\
\hline need & 2 & decrease & 1 & undermine & 1 & & \\
\hline
\end{tabular}


After retrieval, we got 120 concordance lines with ability in the ICLE, out of which we sorted out $19 \mathrm{~V}+\mathrm{N}$ collocation by tagging manually. The most commonly used verbs were have, lose, use, prove, and need as shown in Table 3. Among the 19 collocations, only two of them were not correct collocations. They were "descapacite ... ability" and "omit ... ability" as listed below:

22) As a result, there are many consequencies that television has occasioned like: First, television has destroied the Communication that there was in homes and with friends. Second, has descapacited the ability of imagination because there is not reading

23) It should focus on the most important and fundamental soldier 's skills as handling with a gun, being able to use gas mask, etc. We cannot omit also their ability to work in groups, comprehend the military rules

In Ex. 22, the learner intended to express the meaning of "destroy the ability", but he used a word that didn't exist in English. In Ex. 23, the correct form should be "neglect to develop their ability".

Compared with Chinese learners, the rate at which international learners used the $\mathrm{V}+\mathrm{N}$ collocation of ability was almost the same as Chinese learners. However, their production of the collocation was more natural and correct. In the ICLE, only two errors were found. However, in the CLEC more errors were detected and some of them appeared repeatedly. For example, there were 10 instances of the collocation "train ability" in the CLEC. Therefore, Chinese learners have greater chances of making collocation errors than international learners.

Moreover, international learners behaved in a more native-like way in terms of collocation structure. They frequently used such collocations as "have/ lose/ use/ prove/ possess/ need/ reduce/ demonstrate... ability", which also had a high frequency in the BNC. In addition, international learners used more collocations with a negative semantic prosody than Chinese learners did. For example, 4 out of the 19 collocations used by international learners had a negative semantic meaning; and they are "lose/reduce/impair/ undermine/decrease...ability". However, Chinese learners only used one such collocation: lose... ability. The difference reflects the gap between Chinese learners and international learners in using collocations.

\section{Conclusions}

The $\mathrm{V}+\mathrm{N}$ collocation of ability from the BNC, CLEC, and ICLE was collected and analyzed. The major findings are summarized as below:

First, collocation errors are common in Chinese learners' writings, especially the $\mathrm{V}+\mathrm{N}$ collocation. Among the six types of collocation errors, the number of $\mathrm{CC} 3$, i.e. $\mathrm{V}+\mathrm{N}$ collocation errors, is the greatest. This may suggest that Chinese learners have difficulty in acquiring and using the $\mathrm{V}+\mathrm{N}$ collocation.

Secondly, a distinct difference can be spotted between Chinese learners and English native speakers in using the collocation. Due to the limit of their vocabulary, Chinese learners tend to overuse the collocations that have an equivalent in Chinese, and underuse the collocations with a negative semantic prosody.

Finally, a substantial gap can be found between Chinese learners and international learners with regard to correctness and naturalness of their collocation. In other words, international learners produce more natural collocation than Chinese learners.

\section{References}

Corder, S. P. (1981). Error analysis and interlanguage. Oxford: Oxford University Press.

Ellis, R. (2008). The Study of Second Language Acquisition (2nd ed.). Oxford University Press.

Gui, Shichun, \& Yang, Huizhong. (2002). Chinese Learner English Corpus. Shanghai: Shanghai Foreign Language Education Press.

Gui, Shichun. (2005). An analysis of speech errors of Chinese learner. In Yang Huizhong, Gui Shichun, \& Yang Dafu (Eds.), An Analysis of Chinese Learner's Interlanguage based on CLEC (pp. 1-109). Shanghai: Shanghai Foreign Language Education Press.

Nemser, W. (1971). Approximative systems of foreign language learners. International Review of Applied Linguistics, 1971(9), 115-123.

Nesselhauf, N. (2003). The Use of Collocations by Advanced Learners of English and Some Implications for Teaching. Applied Linguistics, 2003(2), 223-242.

Selinker, L. (1992). Rediscovering Interlanguag. London \& New York: Longman.

Selinker, L., \& Lakshmanan, U. (1992). Language transfer and fossilization: The multiple effects principle. In Gass, S. M., \& Selinker, L. (Eds.), Language Transfer in Language Learning (pp. 197-216). 
Amsterdam/Philadelphia: John Benjamins.

Sinclair, J. (1991). Corpus, concordance, and collocation. Oxford: Oxford University Press.

Wang, Haihua, \& Zhou, Xiujuan. (2009). A study on Chinese learners' development of verb + noun collocation behavior: a corpus-driven methodology. Waiyu Xuekan, 2009(6), 59-62.

\section{Copyrights}

Copyright for this article is retained by the author(s), with first publication rights granted to the journal.

This is an open-access article distributed under the terms and conditions of the Creative Commons Attribution license (http://creativecommons.org/licenses/by/3.0/). 